\title{
A human factor analysis to mitigate fall risk factors in an Aerospace Environment
}

Dr. Joylene H. Ware

$3^{\text {rd }}$ International Conference on Applied Human Factors and Ergonomics

Miami, Florida

July 17-20, 2010 


\section{Introduction}

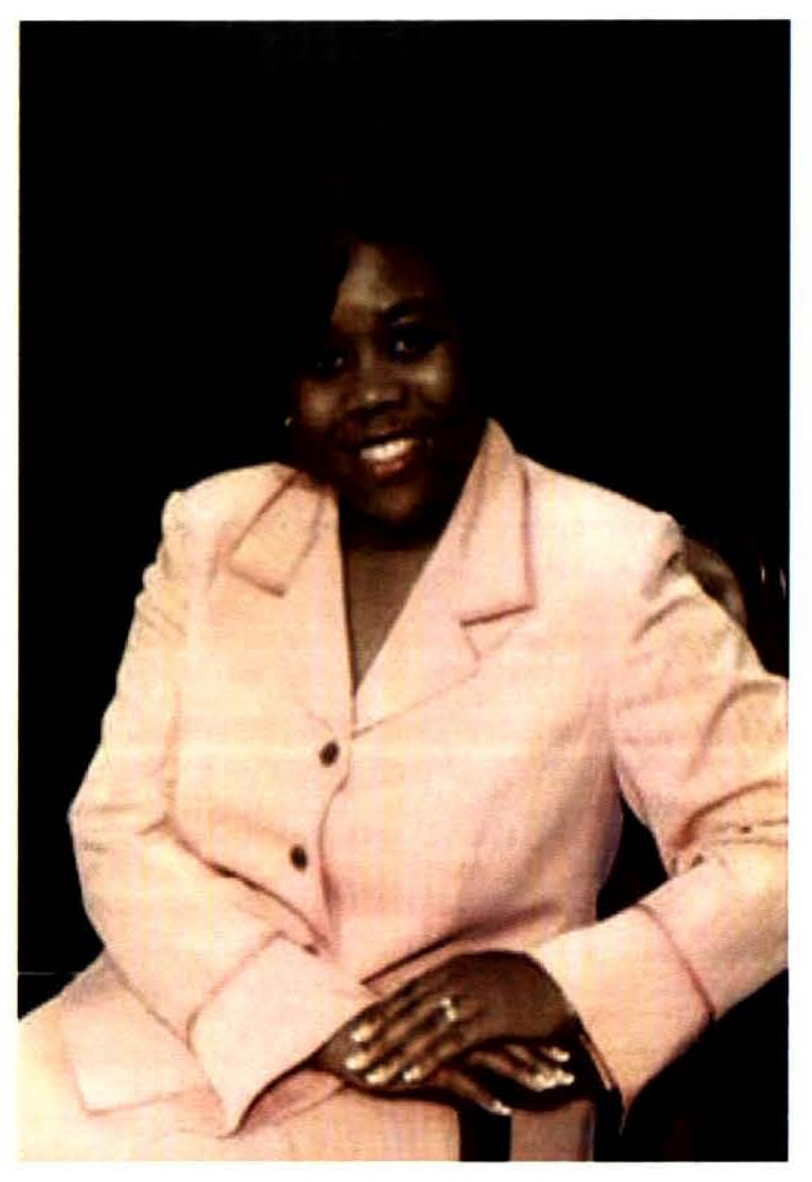

- UCF: Ph.D in Industrial Engineering, (Human Factors/Ergonomics)

- FSU: M.S. in Industrial Engineering (Engineering Management)

- FAMU: B.S. in Chemical Engineering (Cum Laude)

- Engineer at NASA/Kennedy Space Center

- Adjunct Professor at Florida Institute of Technology and Valencia Community College 


\section{Presentation Outline}

- Introduction

- Problem Statement

- Research Hypotheses

- Literature Review

- Research Methodology

- Research Results

- Discussion

- Conclusion

- Questions/Answers 


\section{What is a Fall?}

Fall is "an event which results in a person coming to rest unintentionally on the ground or other lower level, not by the result of a major intrinsic event such as (stroke) or overwhelming hazard." (Tinetti, 1988) Falls are under the umbrella of System Safety. 


\section{Human Body and Falls}

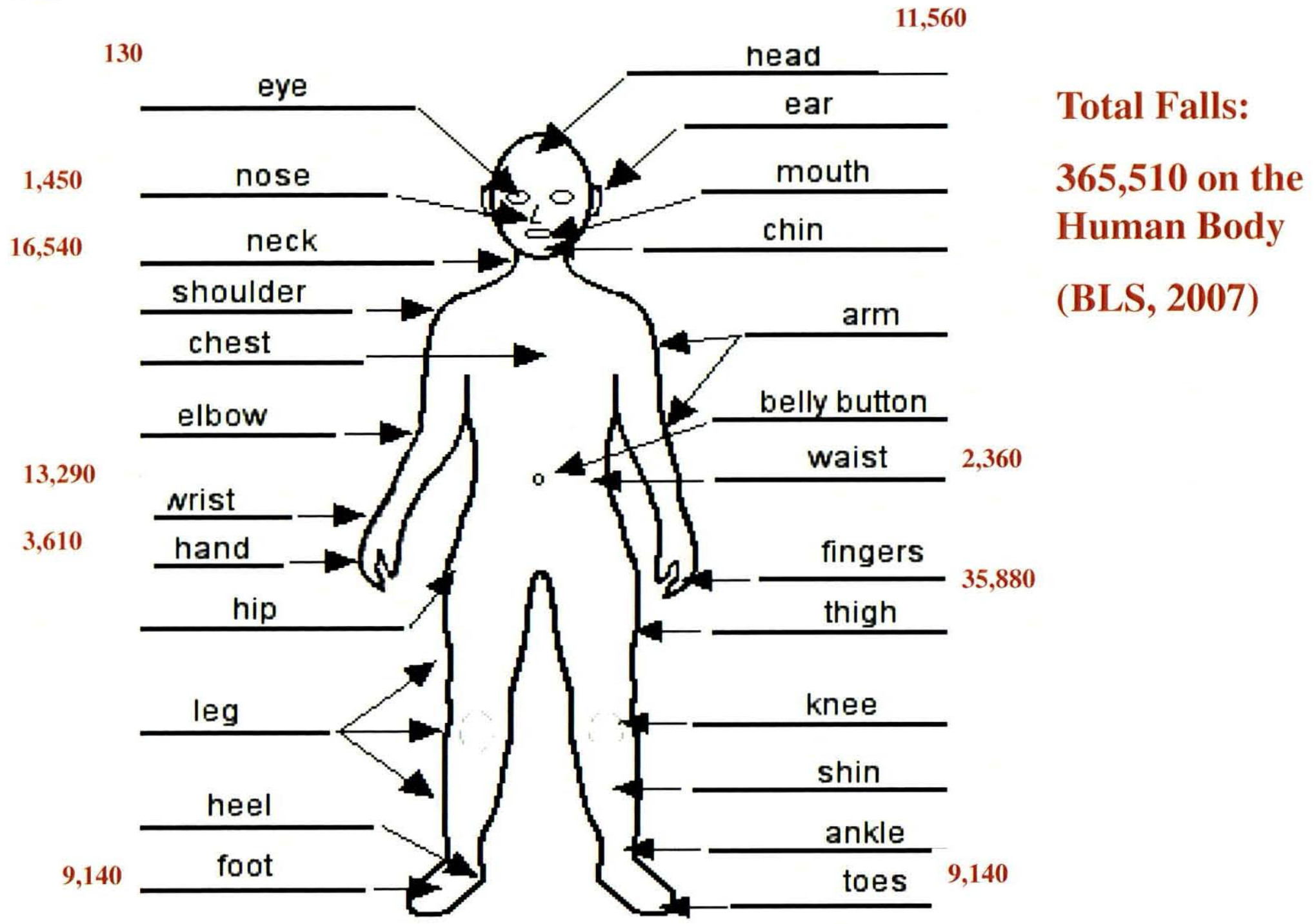

Note: Falls impact the entire human body. According to BLS 2007, there were approximately 300k falls that affected the human body. 


\section{Falls in an Aerospace Environment}

- High risk exists in multiple tasks

- Work is performed at excessive heights

- Potential for high consequence outcomes

- Unique characteristics of environment and equipment 


\section{Problem Statement}

- There are NASA/KSC environments where employees are required to perform tasks from heights that are high risk for falls.

- To address the issue NASA contracted with Gravitec Systems Inc., a fall-protection engineering firm to developed a hazard ranking system to assess fall hazards.

- The hazard ranking system was established based on the assumption that multiple factors such human factors, environmental factors, and working conditions have a uniform influence on falls. (The ranking system has not been validated) 


\section{Research Purpose}

-Research, develop, and validate a fuzzy AHP quantifiable model that can be applied in aerospace environments

- Validate the present of fall hazards at NASA/KSC

-Validate the Gravitec model

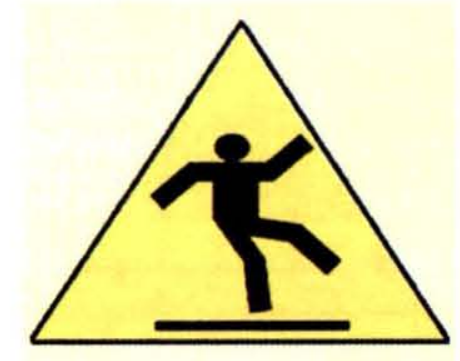




\section{Research Hypotheses (Null and Alternative)}

- $\quad \mathbf{H}_{\mathbf{0}}$ : The development of a conceptual model that characterizes risk factors can be useful in reducing the likelihood of falls in NASA Ground Support Operations

- $\quad \mathbf{H}_{1:}$ The development of a conceptual model that characterizes risk factors cannot be useful in reducing the likelihood of falls in NASA Ground Support Operations

- $\quad \mathbf{H}_{\mathbf{0}}$ : A fuzzy analytical hierarchy process model can be developed and validated to predict the likelihood of falls in NASA Ground Support Operations.

- $\quad \mathbf{H}_{1}$ : A fuzzy analytical hierarchy process model can not be developed and validated to predict the likelihood of falls in NASA Ground Support Operations.

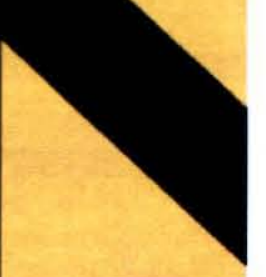




\section{Theoretical Foundation}

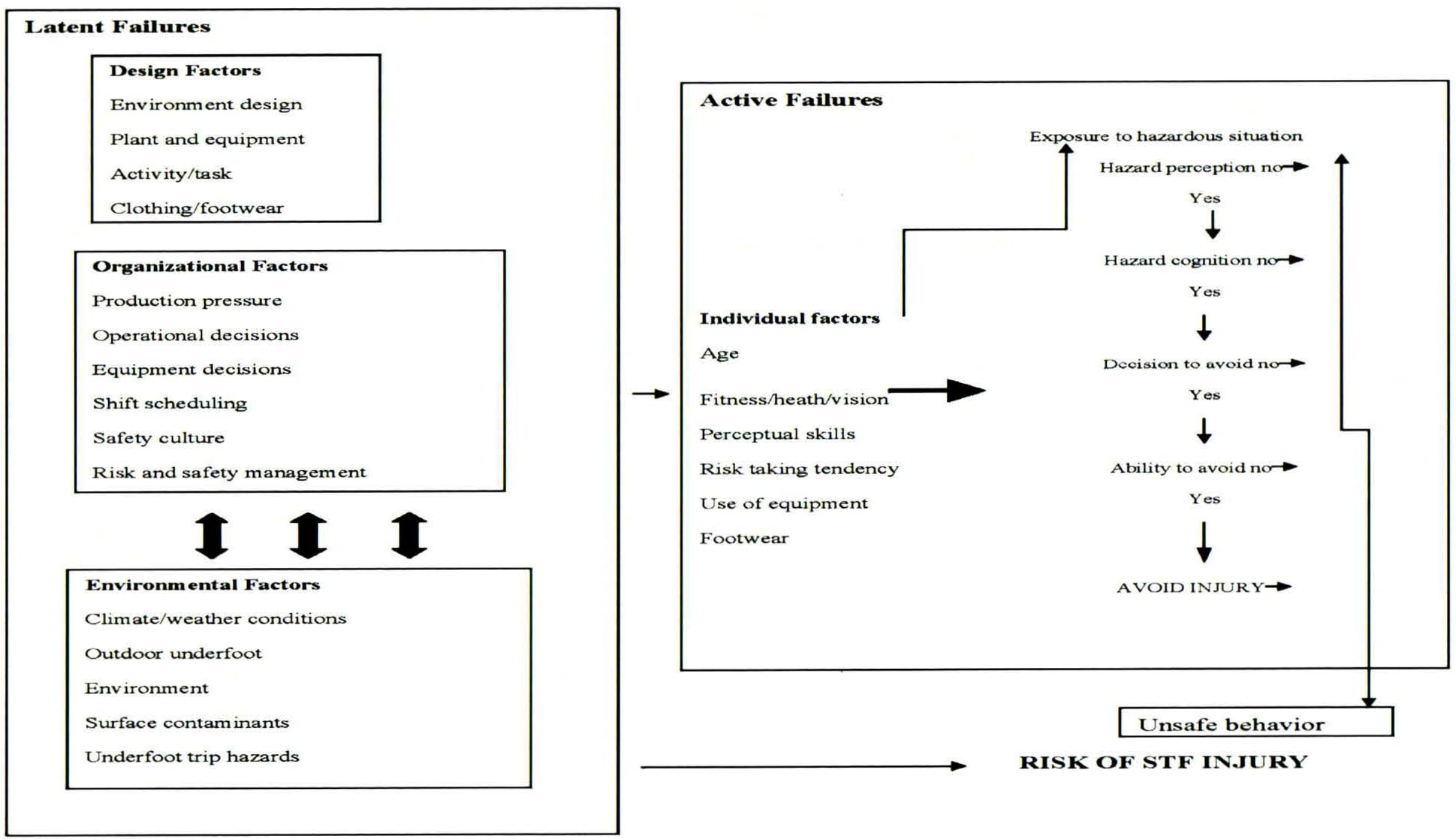

Note: The information processing and ergonomic model is the theoretical basis for the research, categorization of risk factors, and the model development. In this theoretical model, there is a risk of slip, trips, and falls. Falls are a greater risk in an aerospace environment. 


\section{Comparative Analysis}

\section{Multiple Factors that contribute to falls}

General Work Environment

- $\quad$ Experience (OF)

- Job and Safety Program (OF)

- Type of Task/Activity (TF)

- $\quad$ Sex/Gender (HF)

- $\quad$ Load weight (TF)

- $\quad$ Environmental Conditions (EF)

- $\quad$ Task Frequency (TF)

- $\quad$ Task Duration (TF)

- $\quad$ Slip and Trip (HF)

- Environmental Surface (EF)

- $\quad$ Slip and Trip (HF)

- $\quad$ Poor Lighting (EF)

- $\quad$ Day of the week (EF)

- Occupation/Industry sector (OF)

- Coefficient of Friction (EF)

- $\quad$ Time of Day for the fall (EF)

- Coefficient of Friction (EF)

- $\quad$ Fall Distance (EF)

- $\quad$ Age (HF)
Aerospace Environment (NASA Ground Support Operations)

- Worker Interference (HF)

- Number of Workers (HF)

- $\quad$ Age (HF)

- $\quad$ Fall Distance (EF)

- Environmental Conditions (EF)

- Environmental Surface (EF)

- Task Duration (TF)

- Task Frequency (TF)

- $\quad$ Fall Hazard Severity (OF)

- $\quad$ Fall Hazard Protection (OF)

- $\quad$ Fall Hazard Occurrence (OF)

- $\quad$ Task Proximity (TF)

Legend

OF-Organizational Factor

EF-Environmental Factor

TF-Task Related Factor

HF-Human/Personal Factor

Benchmark: The risk factors were observed multiple times ( 3 reoccurrences) in the literature and there was a common thread in the Bureau of Labor Statistics (BLS) Data, Liberty Mutual Data, Mishap Data, IRIS, Empirical Studies, Safety Mishap Data, and NASA/Gravitec Fall Hazard Analysis Report. The risk factors will be assessed and used in the fuzzy AHP model. The list is not conclusive. 


\section{Final Conceptual Model}

Environmental Factors

Organizational Factors

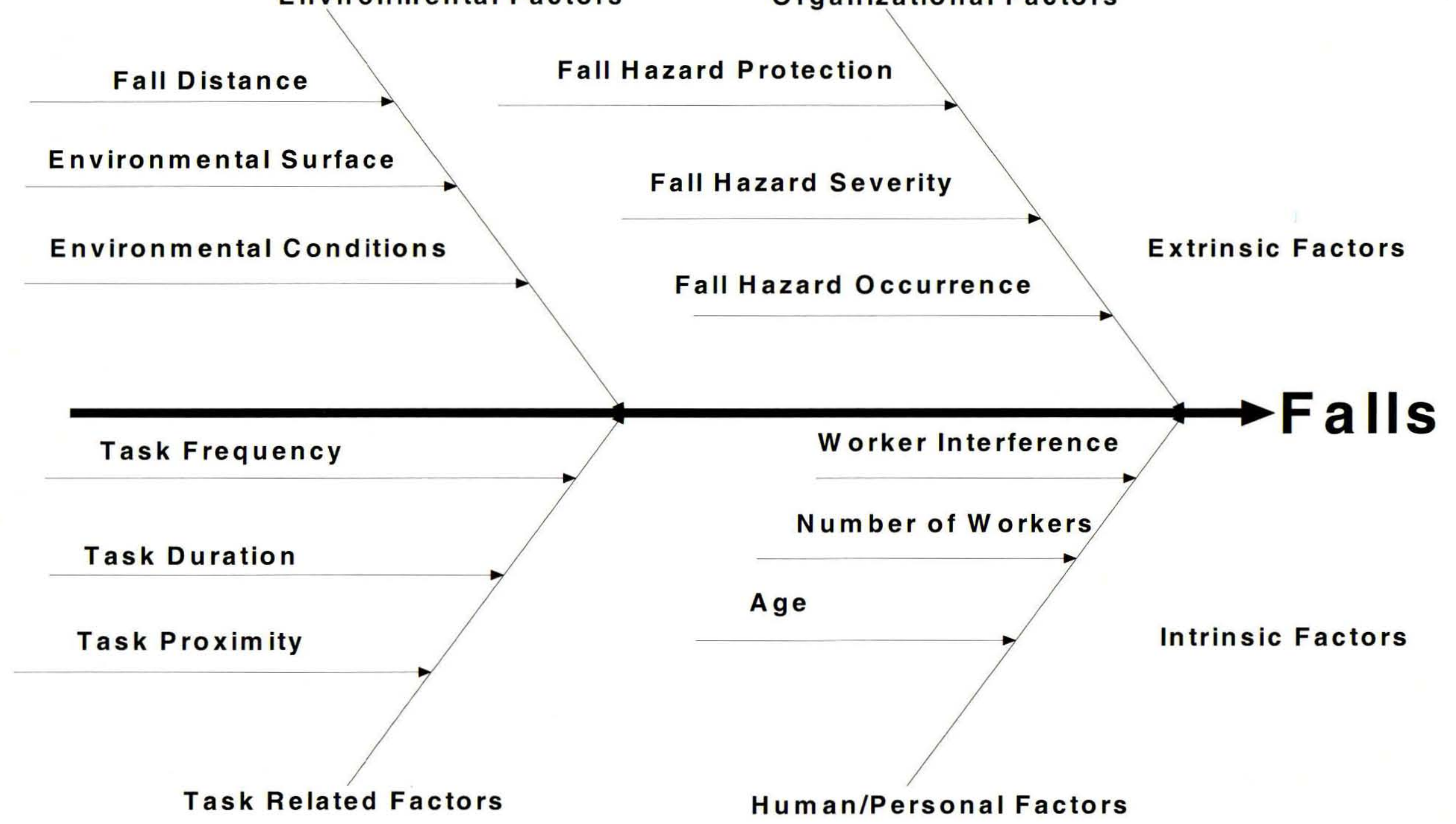




\section{Research Gaps and Objectives}

Research Gaps

\section{Research Objectives}




\section{Research Phases}

1. Knowledge Acquisition

2. Data Collection

3. Subject Matter Experts' (SMEs) interviews

4. Analytical Hierarchy Process (AHP)

5. Weight Validation

6. Fuzzification of variables

7. Membership Functions Development

8. Fuzzy Qualification using Fuzzy set theory

9. Fuzzy Quantification using Fuzzy set theory

10. Model Development

11. Model Usability

12. Model Validation 


\section{Research Variables}

-Dependent Variable: Fall (effect)

-Independent Variable: Factors that contribute to falls (cause) are the following:

- task related

- human/personal

- organizational

- environmental 


\section{Research Questions}

- What are the contributing risk factors that influence falls in the workplace?

- How do we quantify contributing risk factors that influence falls in NASA ground support operations?

- What is aggregate risk value of these risk factors on falls?

- How we will predict the likelihood of falls? 


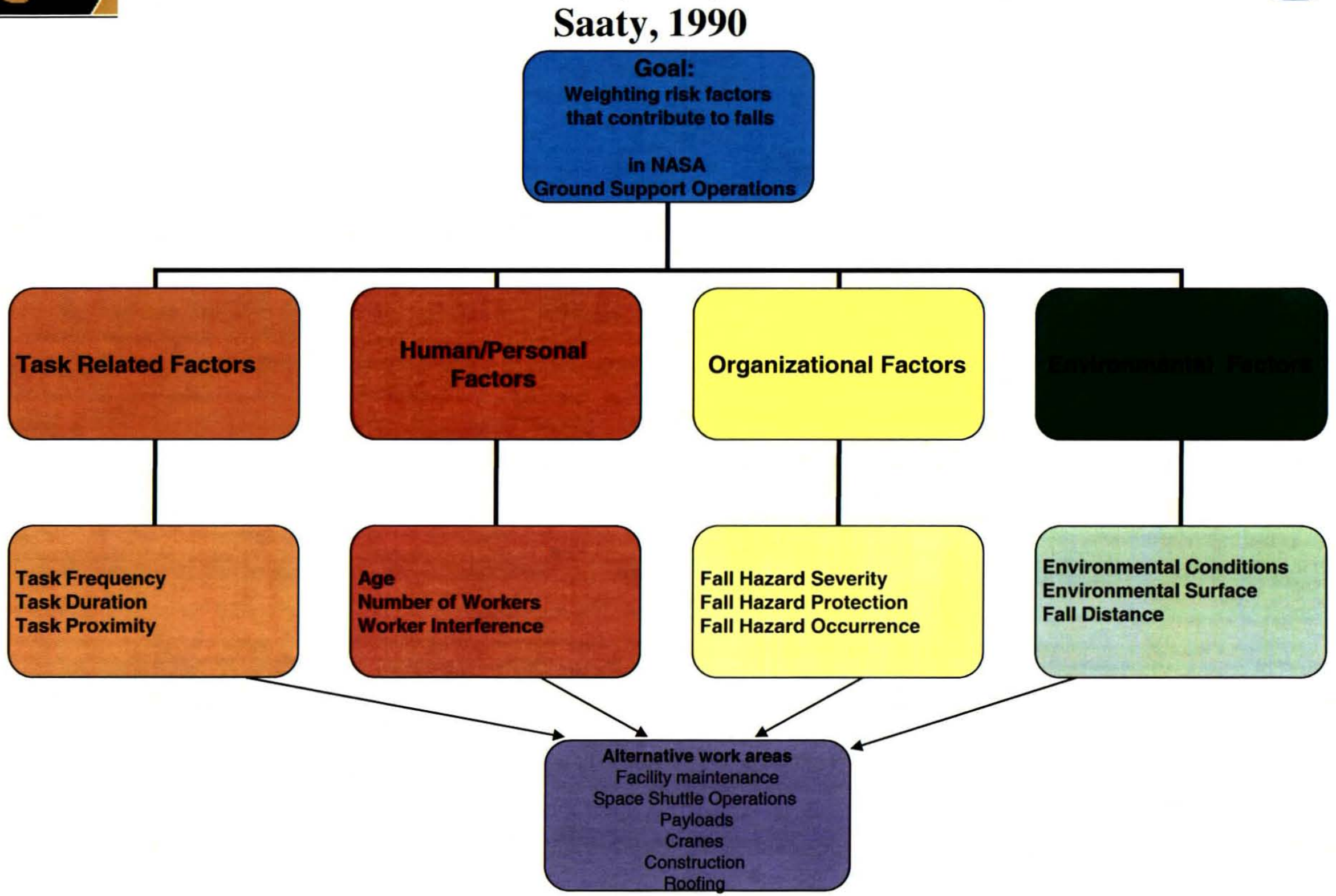




\section{Subject Matter Experts (SMEs)}

\begin{tabular}{|l|l|}
\hline Team 1 & Team $\mathbf{2}$ \\
\hline 1 Fall Protection Expert & 1 Fall Protection Expert \\
\hline 1 Human Factors Expert & 1 Human Factors Expert \\
\hline 1 Safety Expert & 1 Safety Expert \\
\hline
\end{tabular}




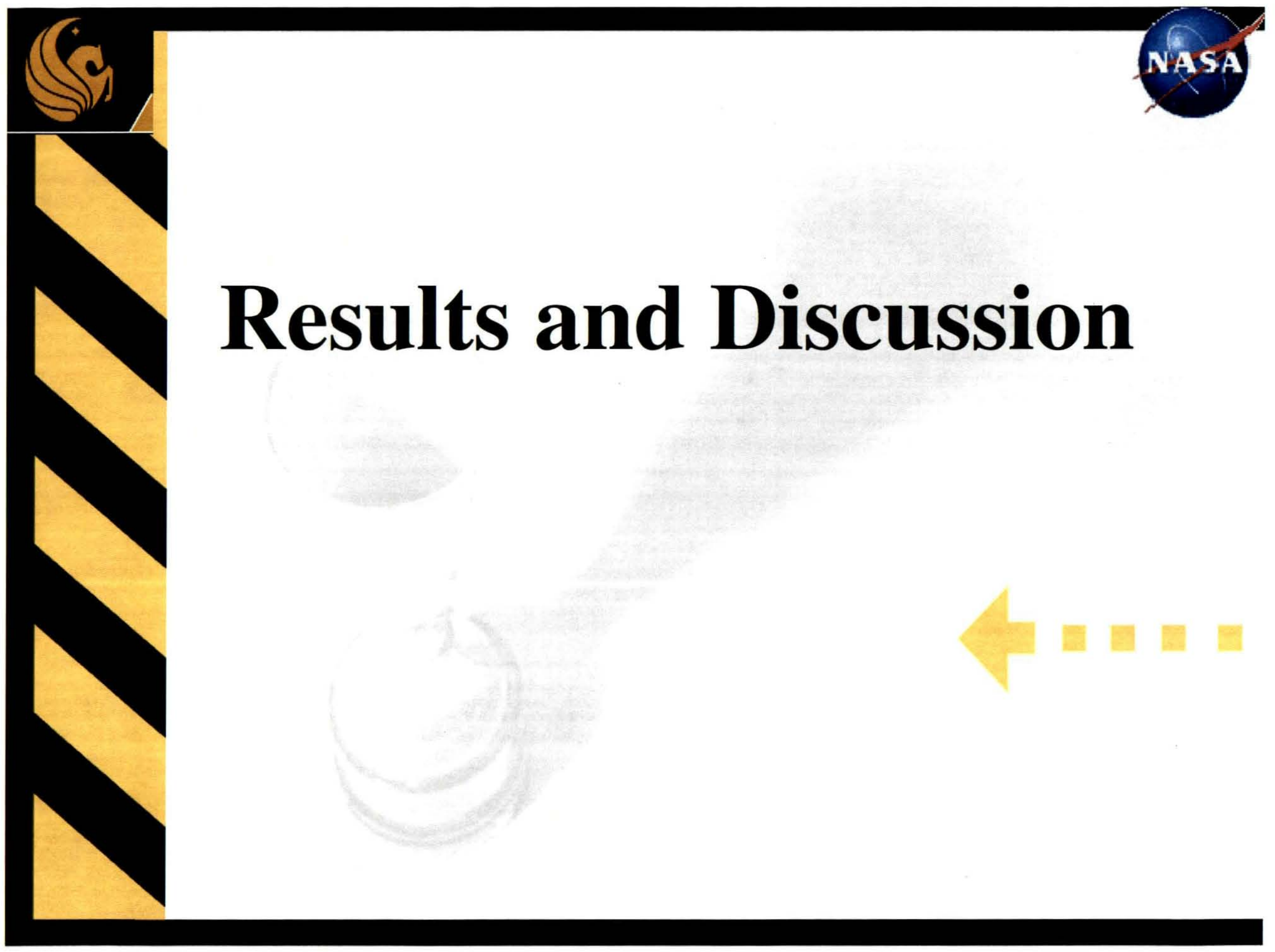




\section{Risk Factors Relative Weights Expert Choice Results}

Task Factors

Human/Personal Factors

Environmental Factors

Categorical Factors
Task Frequency

Task Proximity

Task Duration

Inconsistency $=\mathbf{0 . 1 1}$

with 0 missing judgments.

\section{Worker Interference}

Number of Workers

Age

Inconsistency $=0.01$

with 0 missing judgments.

Environmental Suface

Environmental Condition

Fall Distance

Inconsistency $=0.11$

with 0 missing judgments.

Fall Hazard Oœcurenœ

Fall Hazard Protection

Fall Hazard Severity

Inconsistency $\mathbf{~} \mathbf{0 . 0 0}$

with 0 missing judgments.

Task Related Factors

Human/Personal Factors

Organizational Factors

Environmental Factors

Inconsistency $=\mathbf{0 . 0 1}$

with 0 missing judgments.
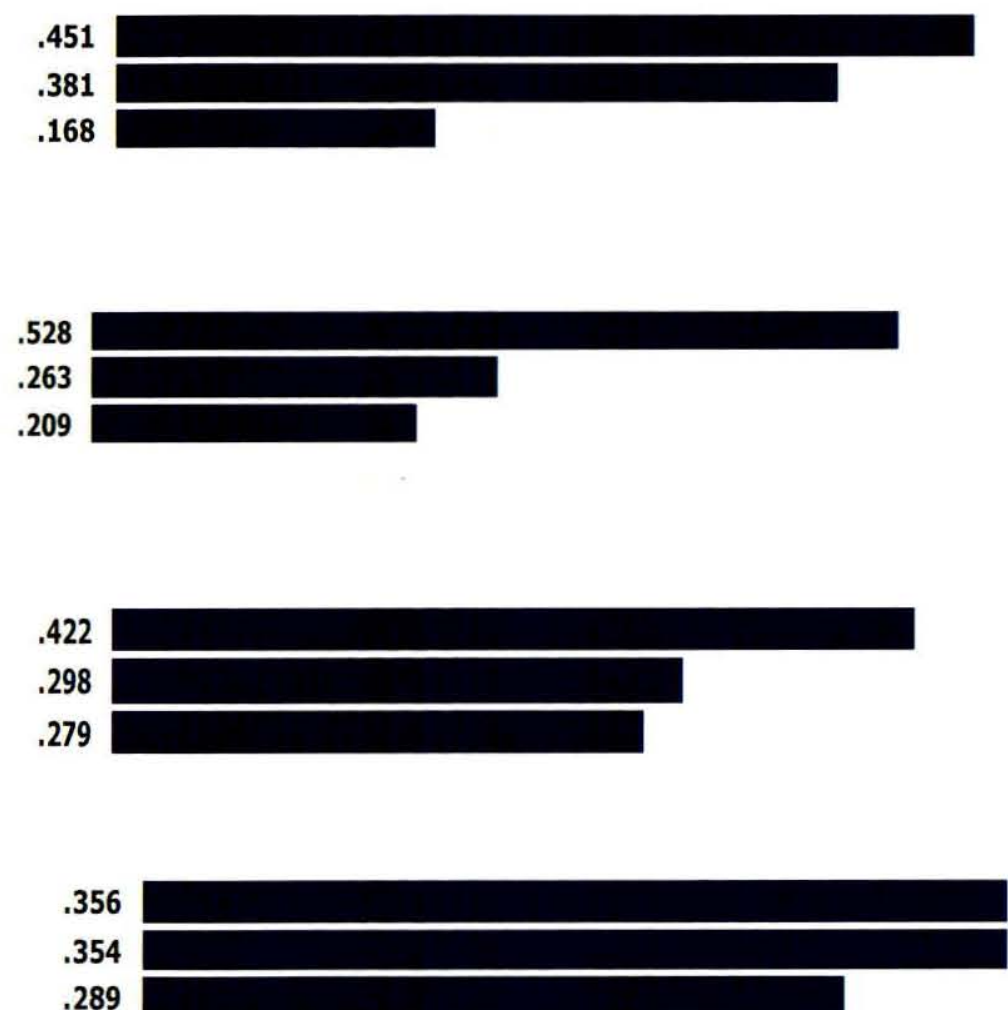

.289

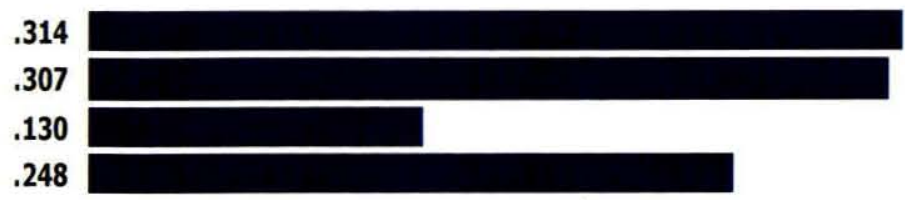




\section{Synthesis}

\section{Synthesis with respect to:}

Goal: Weighting risk factors that contribute to falls in NASA Ground Support Opertations

Overall Inconsistency = .07

Task Duration
Task Frequency
Task Proximity
Age
Number of Workers
Worker Interference
Fall Hazard Severity
Fall Hazard Occurence
Fall Hazard Protection
Environmental Suface
Environmental Condition
Fall Distance

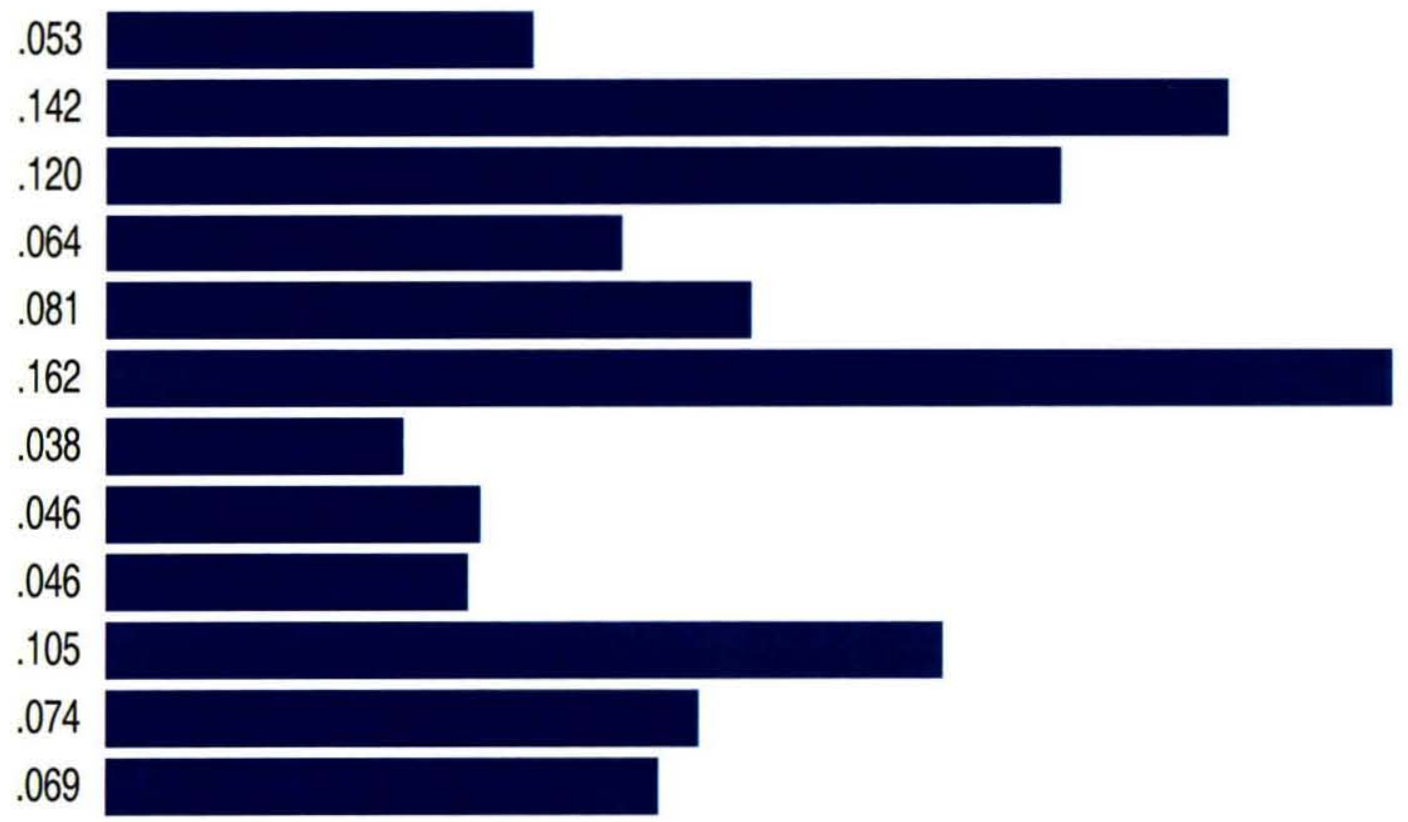

Note: The Synthesis with respect to the goal lists the global weights for the risk factors. Worker Interference (0.162), Task frequency $(\mathbf{0 . 1 4 2})$, and task proximity $(\mathbf{0 . 1 2 0})$ are the highest contributing risk factors to falls. Therefore, task related factors are the leading risk factors that contribute to falls. 


\section{Weight Validation}

The values in the pairwise comparison matrix are the geometric averages between the SMES judgments of risk factors. The sum is the total value for each column or the categorical risk factor.

\begin{tabular}{|c|c|c|c|c|}
\hline \multicolumn{5}{|c|}{$\begin{array}{l}\text { Weight Validation } \\
\text { Pairwise Comparison Matrix from Expert Choice Software }\end{array}$} \\
\hline & Task Related & Human & Organizational & Environmental \\
\hline Task Related & 1 & 1 & 2.5 & 1.25 \\
\hline Human/Personal & 1 & 1 & 2.84 & 1 \\
\hline Organizational & 0.39 & 0.35 & 1 & 1.51 \\
\hline Environmental & 0.8 & 1 & 0.6 & 1 \\
\hline Sum & 3.19 & 3.35 & 7.3 & 4.76 \\
\hline
\end{tabular}

The values in the following table were determined by dividing each entry in the pairwise comparison matrix by the sum. The subject matter experts calculated the average of results for each categorical risk factor, which is the priority vector and compared it to the relative weights from Expert Choice Software. There results are similar. Therefore, the weights are confirmed valid.

\begin{tabular}{|c|c|c|c|c|c|c|c|}
\hline \multicolumn{4}{|l|}{ Risk Factor } & \multicolumn{2}{|c|}{ Priority Vector } & Relative Weight & Rank \\
\hline Task Related & 0.313 & 0.298 & 0.342 & 0.262 & $\mathbf{0 . 3 0 4}$ & $\mathbf{0 . 3 1 4}$ \\
\hline Human/ Personal & 0.313 & 0.298 & 0.389 & 0.210 & $\mathbf{0 . 3 0 2}$ & $\mathbf{0 . 3 0 7}$ \\
\hline Environmental & 0.2501 & 0.298 & 0.0821 & 0.210 & $\mathbf{0 . 2 1}$ & $\mathbf{0 . 2 4 8}$ & $\mathbf{3}$ \\
\hline Organizational & 0.122 & 0.104 & 0.136 & 0.317 & $\mathbf{0 . 1 7}$ & $\mathbf{0 . 1 3}$ \\
\hline
\end{tabular}




\section{NASA Safety Index}

Frequency Index (F)

This index quantifies how frequently worker(s) would be exposed to the particular fall hazard:

\begin{tabular}{|c|c|c|}
\hline Term & $\mathbf{F}$ & Description \\
\hline Never & 0.1 & Never been accessed. \\
\hline Occasionally & 0.9 & Worker(s) at the location once every 2 to 10 years \\
\hline Annually & 1.0 & Worker(s) at the location or task is done once or twice per year. \\
\hline Monthly & 1.1 & Worker(s) at the location 3-12/yr. Monthly maintenance, "as needed" work \\
\hline Weekly & 1.2 & Worker(s) at the location 13-52 /yr. Weekly maintenance, "as needed" work \\
\hline Daily & 1.3 & Worker(s) at the location on a daily basis or once / shift. \\
\hline Shift & 1.4 & Worker(s) at the location more than once per shift or several time \\
\hline
\end{tabular}

2

\section{Occurrence Index (O)}

This index quantifies how often the particular hazard is found at the facility being studied:

\begin{tabular}{ccl}
\hline Occurrence Index $(0)$ & & \\
\hline Term & 0 & Description \\
\hline Unique & 1.0 & Hazard occurs at only one location. \\
\hline Rare & 1.1 & Hazard occurs at two locations. \\
\hline Common & 1.2 & Hazard occurs at $3-10$ locations. \\
\hline Very Common & 1.3 & Hazard occurs at more than $11-50$ locations. \\
Recurring & 1.4 & Hazard occurs at more than 50 locations.
\end{tabular}

3

Proximity Index (X)

This index reflects how close workers normally get to the hazard, as follows:

\begin{tabular}{|c|c|c|}
\hline Term & $\mathbf{x}$ & Description \\
\hline Near & 1.0 & Worker(s) from 6 to 10 feet $(1.8$ to $3.0 \mathrm{~m})$ an improperly guarded fall hazard \\
\hline Close & 1.1 & Worker(s) from 3 to 6 feet $(0.9$ to $1.8 \mathrm{~m})$ of an improperly guarded fall hazard \\
\hline Very Close & 1.2 & Worker(s) from 1 to 3 feet $(0.3$ to $0.9 \mathrm{~m})$ of an improperly guarded fall hazard \\
\hline Immediate & 1.3 & Worker(s) Directly exposed to an unguarded fall hazard or working from a ladde \\
\hline
\end{tabular}




\section{Level of Existence}

\begin{tabular}{|c|c|}
\hline Level of Existence & \\
\hline Conceptual Model Factors & Ranges for Fuzzy Model (Left to Right) \\
\hline \multicolumn{2}{|l|}{ Task Related Factors } \\
\hline Task Frequency & 0.1 to 2.0 \\
\hline Task Duration & 1.0 to 2.0 \\
\hline Task Proximity & 1.0 to 2.0 (in relation to Fall Distance) \\
\hline & \\
\hline \multicolumn{2}{|l|}{ Environmental Factors } \\
\hline Fall Distance & $0-10 \mathrm{ft}=\operatorname{low}(0.33), 11-15 \mathrm{ft}=$ medium $(0.66),>25 \mathrm{ft},=$ high $(1.0)$ \\
\hline Environmental Surface & 0.9 to 2.0 \\
\hline Environmental Conditions & 0.9 to 2.0 \\
\hline \multicolumn{2}{|l|}{ Human/Personal Factors } \\
\hline Worker Interference & 1.0 to 2.0 \\
\hline Number of workers & 1 to 5 (dependent on workers) \\
\hline Age & $21-70$ (years) \\
\hline \multicolumn{2}{|l|}{ Organizational Factors } \\
\hline Fall Hazard Severity & 1 to 10 \\
\hline Fall Hazard Protection & 0.1 to 2.0 \\
\hline Fall Hazard Occurrence & 1.0 to 2.0 \\
\hline
\end{tabular}




\title{
Fuzzy Quantification Linear Models Categorical Risk Factors for falls
}

\author{
Task Related Risk Factors \\ $X_{1}=F(T R)=a_{1} w_{1}+a_{2} w_{2}+a_{3} w_{3}+\ldots . a_{n} w_{n}$ \\ Human/Personal Risk Factors \\ $X_{2}=F(H / P)=b_{1} z_{1}+b_{2} z_{2}+b_{3} z_{3} \ldots . . b_{n} z_{n}$
}

Organizational Risk Factors

$X_{3}=F(O)=c_{1} u_{1}+c_{2} u_{2}+c_{3} u_{3}+\ldots . c_{n} u_{n}$

Environmental Risk Factors

where,

$$
X_{4}=F(E)=d_{1} v_{1}+d_{2} v_{2}+d_{3} v_{3}+\ldots . . d_{n} v_{n}
$$

$a=$ task related risk sub-factors relative weight

$\mathrm{b}=$ human/personal risk sub-factors relative weight

$\mathrm{c}=$ organizational risk sub-factors relative weight

$\mathrm{d}=$ environmental risk sub-factors relative weight

$\mathrm{w}=$ task related risk sub-factors level of existence

$\mathrm{z}=$ human/personal risk sub-factors level of existence

$\mathrm{u}=$ organizational risk sub-factors level of existence

$\mathrm{v}=$ environmental risk sub-factors level of existence 


\section{Fuzzy Quantification Linear Models Comprehensive Risk for falls}

$$
Y=e_{1} X_{1}+e_{2} X_{2}+e_{3} X_{3}+e_{4} X_{4}
$$

where,

$\mathrm{Y}=$ comprehensive risk for the given condition

$\mathrm{X}_{1}=$ the risk associated with the task related factors

$\mathrm{e}_{1}=$ weighting factor for the task related factors

$\mathrm{X}_{2}=$ the risk associated with the human/personal factors

$\mathrm{e}_{2}=$ weighting factor for the human/personal factors

$\mathrm{X}_{3}=$ the risk associated with the organizational factors

$\mathrm{e}_{3}=$ weighting factor for the organizational factors

$\mathrm{X}_{4}=$ the risk associated with the environmental factors

$\mathrm{e}_{4}=$ weighting factor for the environmental factors

The weighting factors $\left(\mathrm{e}_{1}, \mathrm{e}_{2}, \mathrm{e}_{3}, \mathrm{e}_{4}\right)$ represent the relative significance of the given risk factor category's contribution to the likelihood of injury.

Note: The comprehensive risk is the aggregate risk value for the prediction of a fall; which is equal to the product of relative weight respective to the categorical risk factors. 


\section{Model Usability}

- Design of Experiment

- Repeated measures analysis

- 15 Subjects

- Between and within subjects

- Agreement of Data

- Variability of Data

- NASA Ground Support Operations

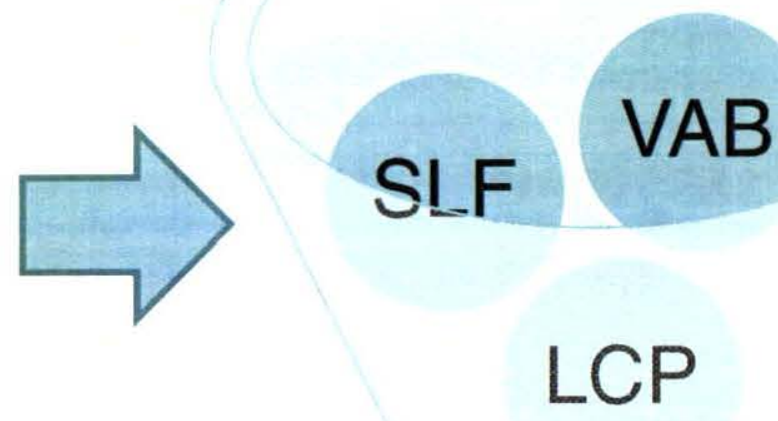

Scenarios

- SLF-Shuttle Landing Facility

- LCP-Launch Complex Payloads

- VAB-Vehicle Assembly Building

NASA Scenarios 


\section{Aggregate Risk Value and Likelihood Rating}

\begin{tabular}{|c|l|l|}
\hline Aggregate Risk Value (Y) & \multicolumn{1}{|c|}{ Risk Associated with Numeric Value } & \multicolumn{1}{|c|}{ Likelihood Rating } \\
\hline $0.00-0.20$ & $\begin{array}{l}\text { Very Low risk: Falls are very unlikely to occur. Strong Controls } \\
\text { are in place. }\end{array}$ & 1 \\
\hline $0.21-0.40$ & $\begin{array}{l}\text { Low risk: Falls are not likely to occur. Controls have minor } \\
\text { limitations and uncertainties. }\end{array}$ & 2 \\
\hline $0.41-0.60$ & $\begin{array}{l}\text { Moderate risk: Falls may occur. Controls exist with some } \\
\text { uncertainties. }\end{array}$ & 3 \\
\hline $0.61-0.80$ & $\begin{array}{l}\text { High risk: Falls are highly likely to occur. Controls have } \\
\text { significant uncertainties. }\end{array}$ & 4 \\
\hline $0.81-1.00$ & $\begin{array}{l}\text { Very high risk: Falls are nearly certain to occur. Controls have } \\
\text { little or no effect. }\end{array}$ & 5 \\
\hline & & \\
\hline
\end{tabular}




\section{NASA Fall Hazard Accepted Scale}

\begin{tabular}{|c|c|c|}
\hline Numerical Risk Value & Risk Associated with the Value & Likelihood Rating \\
\hline $0-5$ & Low Risk Hazards & \\
\hline $6-10$ & Medium Risk Hazards & \\
\hline $10-15$ & & 3 \\
\hline $15-20$ & High Risk Hazards & \\
\hline & & \\
\hline $20-25$ & Dangerous Risk Hazards & \\
\hline & & \\
\hline
\end{tabular}




\section{Shuttle Landing Facility (SLF)
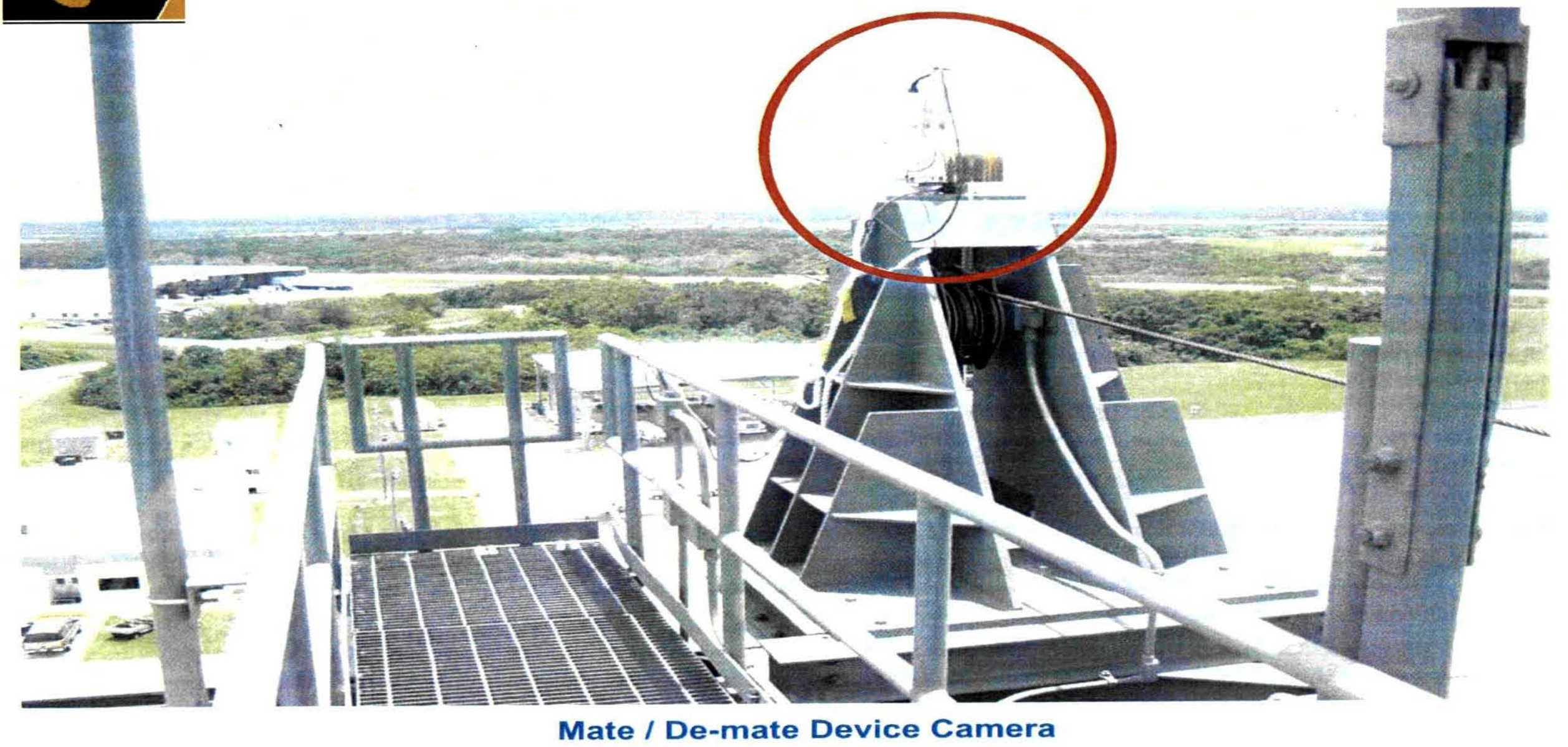

Case Study: A worker 32 years old required to conduct routine maintenance on the camera pictured in the red circle outside the Shuttle Landing Facility. At this site, there is no personal protection equipment. The maintenance includes lens cleaning, adjusting, focusing, etc. Once outside the guardrail railing, workers are exposed to a fall distance is approximately $100 \mathrm{ft}$. to the ground. 


\section{Launch Complex Payloads (LCP)}

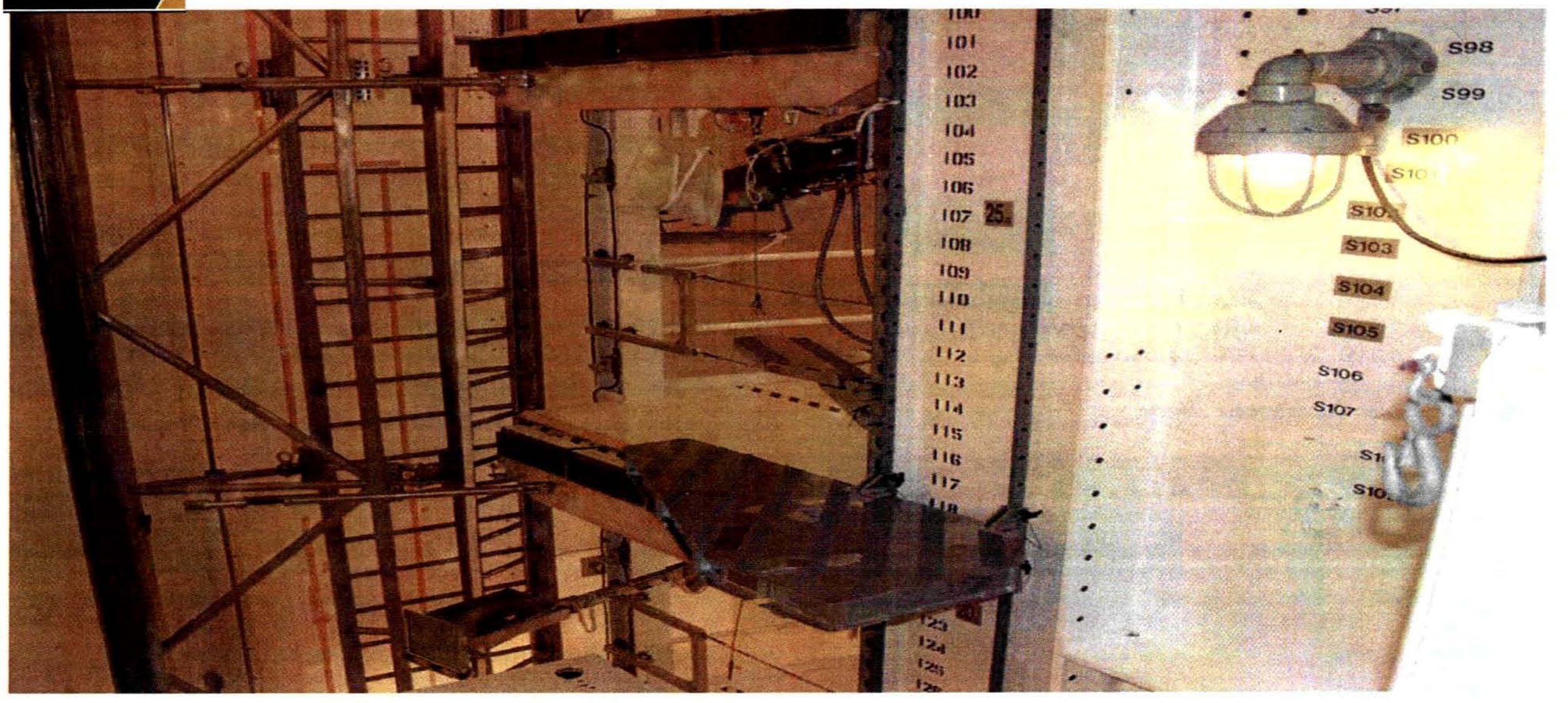

LC 39 A \& B - Payload Platforms

Case Study: A 47 year old worker is working off payload platforms at any level in this NASA/KSC facility on the orbiter payloads. There is minimal lighting in the facility for the workers. The fall distance is $60+\mathrm{ft}$ off platforms. All edges of platforms are unguarded. There is no fall protection equipment present. 


\section{Vehicle Assembly Building (VAB)}

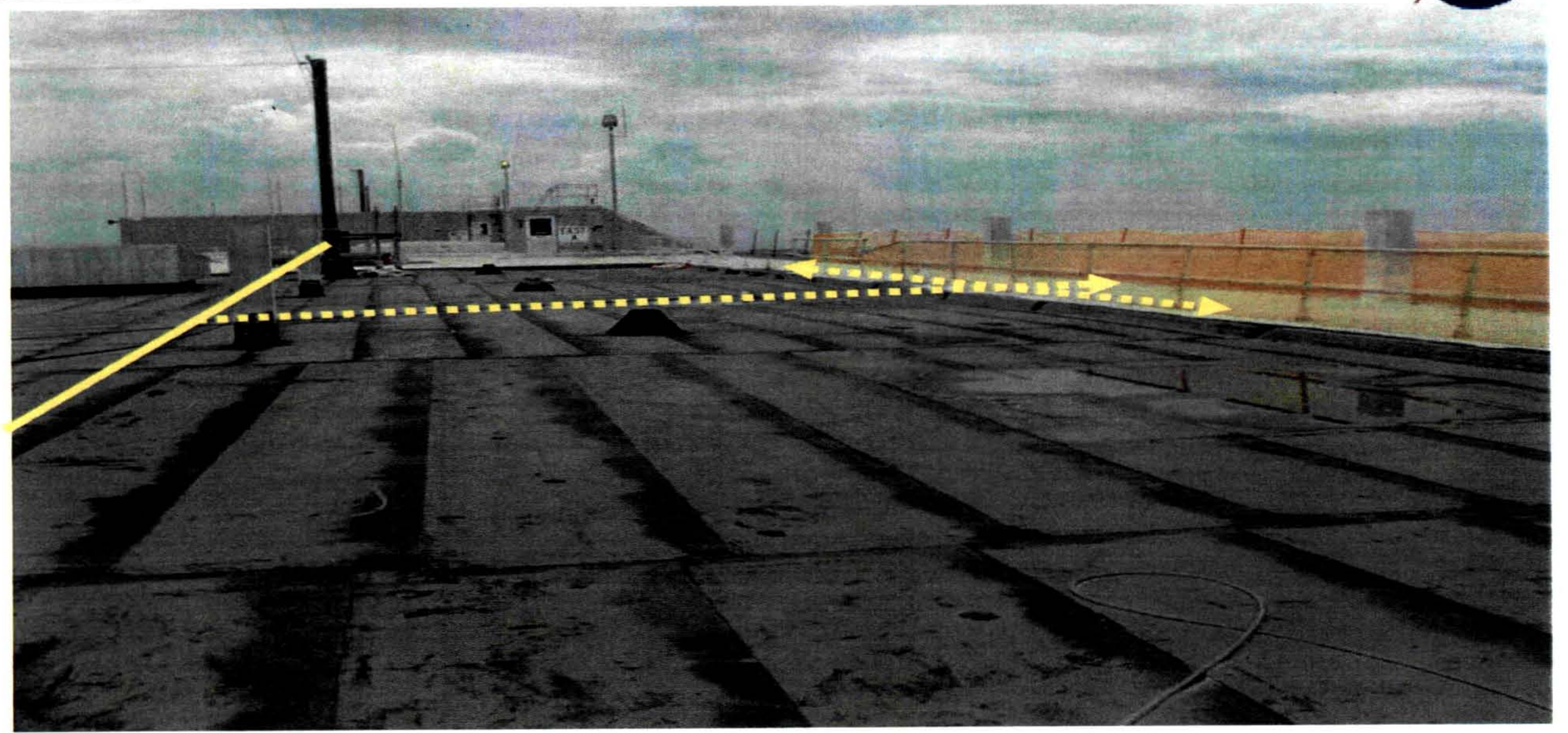

\section{Building Roof}

Case Study: During construction, up to three workers (25 years of age) replace and repair roof material near the edge of the VAB roof. Temporary Horizontal lifeline is installed (solid yellow line). A vertical line lifeline (dotted yellow line) is mounted to adjust the system to the proper length. The fall distance is in excess of $500 \mathrm{ft}$ and contingent upon what location or perimeter of the roof where the fall may occur. 


\section{Scenario Characteristics}

\begin{tabular}{|l|l|l|l|}
\hline Work Area & SLF & LCP & VAB \\
\hline Factor & & & \\
\hline Task Duration & 1.2 -Medium & 1.2 -Medium & 1.2 Medium \\
\hline Task Frequency & 1.1 -Monthly & 1.3 -Daily & 1.4 -Shift \\
\hline Task Proximity & 1.2 -Very close & 1.2 -Very close & 1.2 -Very close \\
\hline Fall Distance & $100 \mathrm{ft}$. & $60 \mathrm{ft}$. & $500 \mathrm{ft}$. \\
\hline Environmental Conditions & 1.2 -Extreme & 1.0 -Good & 1.1 -Variable \\
\hline Environmental Surface & 1.1 -Poor & 0.9 -Excellent & 0.9 Excellent \\
\hline Age & $\mathbf{3 2}$ & $\mathbf{4 7}$ & $\mathbf{2 5}$ \\
\hline \# of workers & 1 worker & 1 worker & 3 workers \\
\hline Worker Interference & 1.0 -Independent & 1.0 Independent & 1.2 -Multiple \\
\hline Fall Occurrence & 1.0 -Unique & 1.2 -Common & 1.2 -Common \\
\hline Fall Severity & 5.0 -Extreme & 5.0 -Extreme & 5.0 -Extreme \\
\hline Fall Protection & 0.75 -Por & $1 .-$ - -one & 0.75 -Poor \\
\hline
\end{tabular}




\section{Scenario Level of Existence}

\begin{tabular}{|l|l|l|l|}
\hline Work Area & SLF & LCP & VAB \\
\hline Factor & & & \\
\hline Task Duration & .4 & .4 & .4 \\
\hline Task Frequency & .95 & .74 & .63 \\
\hline Task Proximity & .4 & .4 & .4 \\
\hline Fall Distance & 1.0 & 1.0 & 1.0 \\
\hline Environmental Conditions & .54 & .18 & .36 \\
\hline Environmental Surface & .36 & 0 & 0 \\
\hline Age & .45 & .94 & .16 \\
\hline Number of workers & 0 & 0 & 1 \\
\hline Worker Interference & 0 & 0 & .4 \\
\hline Fall Occurrence & 0 & .4 & .4 \\
\hline Fall Severity & .88 & .88 & .88 \\
\hline Fall Protection & .68 & .94 & .68 \\
\hline
\end{tabular}

Note: The values were calculated using an Excel (Fuzzification) spreadsheet. 


\section{Model Usability Hypotheses (Null and Alternative)}

- $\quad \mathbf{H}_{\mathbf{0}}$ : The p-value provide the likelihood of obtaining the sample, with its Kendall's coefficient, agreement within subject is due to chance.

- $\quad \mathbf{H}_{1}$ : The p-value provide the likelihood of obtaining the sample, with its Kendall's coefficient, agreement within subject is not due to chance. 


\section{Agreement of Data}

\begin{tabular}{|c|c|c|c|c|c|c|}
\hline Subject & $\begin{array}{l}\text { Kendall } \\
\text { Coefficient }\end{array}$ & Inspected & Matched & $\begin{array}{l}\text { Percentage } \\
(\%)\end{array}$ & P-value & $95 \% \mathrm{Cl}$ \\
\hline Subject 1 & 1.00 & 3 & 3 & 100 & .1353 & $(36.84,100.00)$ \\
\hline Subject 2 & 1.00 & 3 & 2 & 67 & .1353 & $(9.43,99.16)$ \\
\hline Subject 3 & 1.00 & 3 & 3 & 100 & .1353 & $(36.84,100.00)$ \\
\hline Subject 4 & 1.00 & 3 & 3 & 100 & .1353 & $(36.84,100.00)$ \\
\hline Subject 5 & 1.00 & 3 & 3 & 100 & .1353 & $(36.84,100.00)$ \\
\hline Subject 6 & 1.00 & 3 & 3 & 100 & .1353 & $(36.84,100.00)$ \\
\hline Subject 7 & 1.00 & 3 & 3 & 100 & .1353 & $(36.84,100.00)$ \\
\hline Subject 8 & 1.00 & 3 & 3 & 100 & .1353 & $(36.84,100.00)$ \\
\hline Subject 9 & 1.00 & 3 & 3 & 100 & .1353 & $(36.84,100.00)$ \\
\hline Subject 10 & 1.00 & 3 & 3 & 100 & .1353 & $(36.84,100.00)$ \\
\hline Subject 11 & 1.00 & 3 & 3 & 100 & .1353 & $(36.84,100.00)$ \\
\hline Subject 12 & 1.00 & 3 & 3 & 100 & .1353 & $(36.84,100.00)$ \\
\hline Subject 13 & 1.00 & 3 & 3 & 100 & .1353 & $(36.84,100.00)$ \\
\hline Subject 14 & 1.00 & 3 & 3 & 100 & .1353 & $(36.84,100.00)$ \\
\hline Subject 15 & 1.00 & 3 & 3 & 100 & .1353 & $(36.84,100.00)$ \\
\hline
\end{tabular}

Overall

1.00

The following results show that the Kendall Coefficient of Concordance is 1.00, which indicates the outstanding high degree of agreement between and within the subjects. Because the p-values are greater than the alpha level for all subjects, accept the null hypothesis. Agreement within the subject is due to chance and the p-value provide the likelihood of obtaining the sample. As a result, there is a relative agreement among the subjects in the likelihood of falls. 


\section{Variability}

Multiple descriptive statistics for a $95 \%$ confidence interval and t-test are the following:

\begin{tabular}{ll}
\hline Deseriptive Statistic Name & Value \\
\hline Coefficient of Variation & 21.36 \\
Variance & 0.251 \\
Mean & 2.34 \\
Standard deviation & 0.501
\end{tabular}

Therefore, there is minimal variability with the fuzzy AHP modeling. 


\section{Model Validation}

\begin{tabular}{|c|c|c|c|}
\hline Scenario & $\begin{array}{c}\text { Comprehensive } \\
\text { Risk for Falls (Y) }\end{array}$ & $\begin{array}{c}\text { Fuzzy AHP } \\
\text { model: } \\
\text { Predicted } \\
\text { Likelihood } \\
\text { Rating }\end{array}$ & $\begin{array}{c}\text { NASA/KSC } \\
\text { current } \\
\text { Model: } \\
\text { Accepted } \\
\text { Likelihood } \\
\text { Rating }\end{array}$ \\
\hline $\begin{array}{c}\text { Shuttle Landing } \\
\text { Facility (SLF) }\end{array}$ & 0.404 & 2 & 2 \\
\hline $\begin{array}{c}\text { Launch Complex } \\
\text { Payloads (LCP) }\end{array}$ & 0.351 & 2 & 3 \\
\hline $\begin{array}{c}\text { Vehicle Assembly } \\
\text { Building (VAB) }\end{array}$ & 0.451 & 3 & 3 \\
\hline
\end{tabular}




\section{Percentage Error}

$$
\text { \%error }=\frac{(\text { predicted }- \text { accepted })}{\text { accepted }}
$$

For Shuttle Landing Facility (SLF)

$$
0 \% \text { error }=\frac{(2.0-2.0)}{2.0}
$$

$\begin{array}{ll}\text { Shuttle Landing Facility (SLF) } & \mathbf{0 \%} \\ \text { Launch Complex Payloads (LCP) } & \mathbf{3 3 \%} \\ \text { Vehicle Assembly Building (VAB) } & \mathbf{0 \%}\end{array}$




\section{Empirical Approach NASA Risk Scorecard}

\begin{tabular}{|l|}
\hline 5 \\
\hline 4 \\
\hline 3 \\
\hline 2 \\
\hline 1 \\
\hline
\end{tabular}

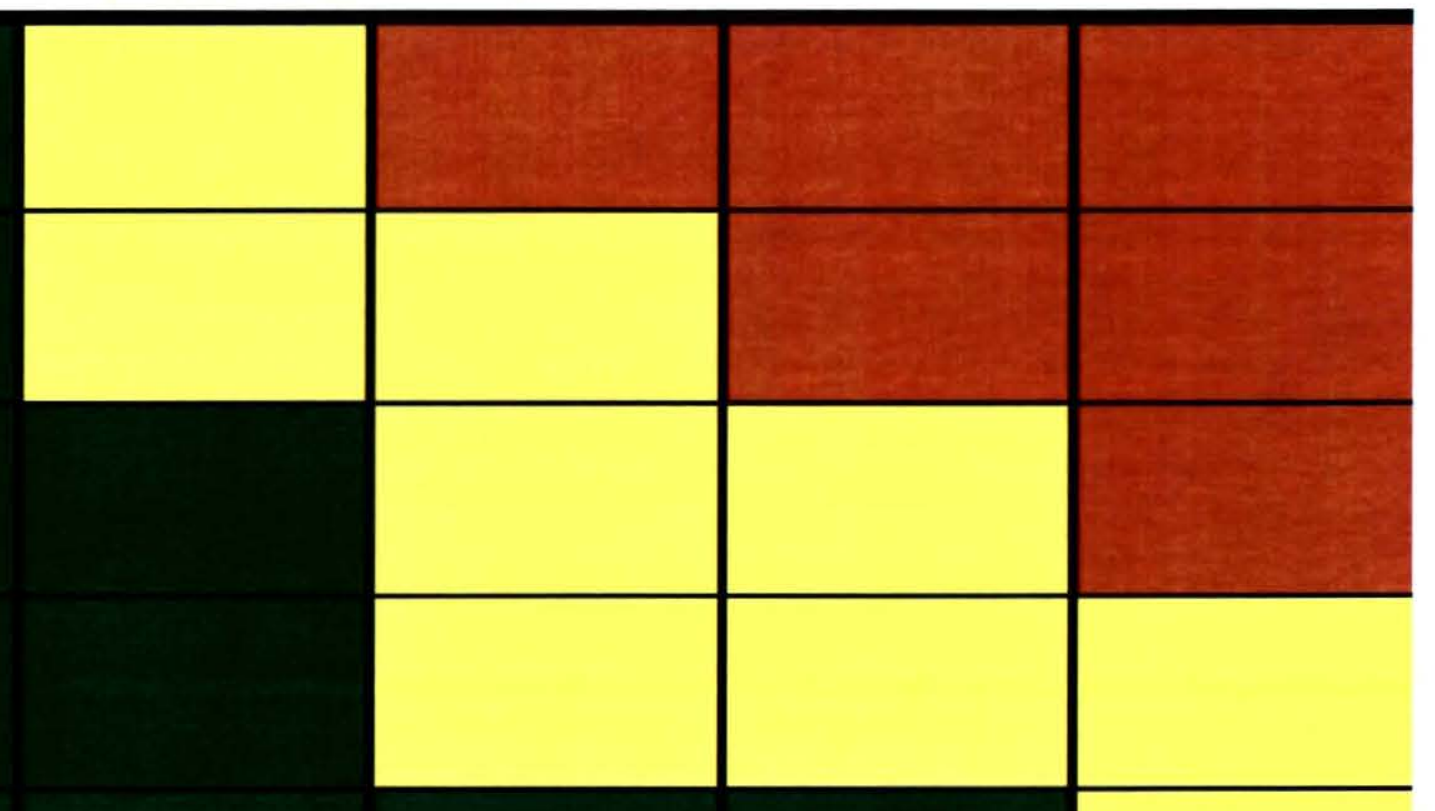

\begin{tabular}{l|l|l|}
1 & 2 &
\end{tabular}

3

4

5 


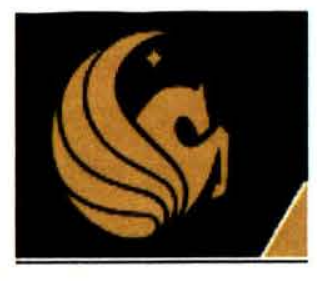

\section{NASA Safety Risk Scorecard Consequence}

\begin{tabular}{|c|c|c|c|c|c|c|}
\hline Consequence & Component & 1 & 2 & 3 & 4 & 5 \\
\hline \multirow[t]{2}{*}{ Safety } & Personnel & Minor Injury & $\begin{array}{l}\text { Injury } \\
\text { requiring first } \\
\text { aid treatment }\end{array}$ & $\begin{array}{l}\text { Injury or } \\
\text { illness; medical } \\
\text { treatment }\end{array}$ & $\begin{array}{l}\text { Severe injury or } \\
\text { hospitalization }\end{array}$ & $\begin{array}{c}\text { Loss of Life or permanently } \\
\text { disabling injury }\end{array}$ \\
\hline & $\begin{array}{c}\text { System Safety } \\
\text { (Falls) }\end{array}$ & $\begin{array}{l}\text { Minor } \\
\text { damage or } \\
\text { non essential } \\
\text { flights assets }\end{array}$ & $\begin{array}{l}\text { Minor damage } \\
\text { to the } \\
\text { program } \\
\text { critical needs }\end{array}$ & $\begin{array}{l}\text { Minor damage } \\
\text { to flight, } \\
\text { Ground Support } \\
\text { assets, }\end{array}$ & $\begin{array}{l}\text { Loss of mission, } \\
\text { major damage to } \\
\text { flight, }\end{array}$ & $\begin{array}{l}\text { Loss of Flight or Ground Assets } \\
\text { or Loss of vehicle prior to } \\
\text { completing its mission } \\
\text { Catastrophic hazard }\end{array}$ \\
\hline & Environmental & $\begin{array}{l}\text { Negligible; } \\
\text { OSHA/EPA } \\
\text { violation non } \\
\text { reportable }\end{array}$ & $\begin{array}{l}\text { Minor } \\
\text { reportable } \\
\text { OSHA/EPA } \\
\text { violation; } \\
\text { reportable }\end{array}$ & $\begin{array}{l}\text { Moderate } \\
\text { OSHA/EPA } \\
\text { violation which } \\
\text { requires } \\
\text { immediate } \\
\text { remediation }\end{array}$ & $\begin{array}{l}\text { Major OSHA/EPA } \\
\text { violation causing } \\
\text { temporary stoppage }\end{array}$ & $\begin{array}{l}\text { Serious or repeat OSHA/EPA } \\
\text { violation; termination of project } \\
\text { or program }\end{array}$ \\
\hline
\end{tabular}




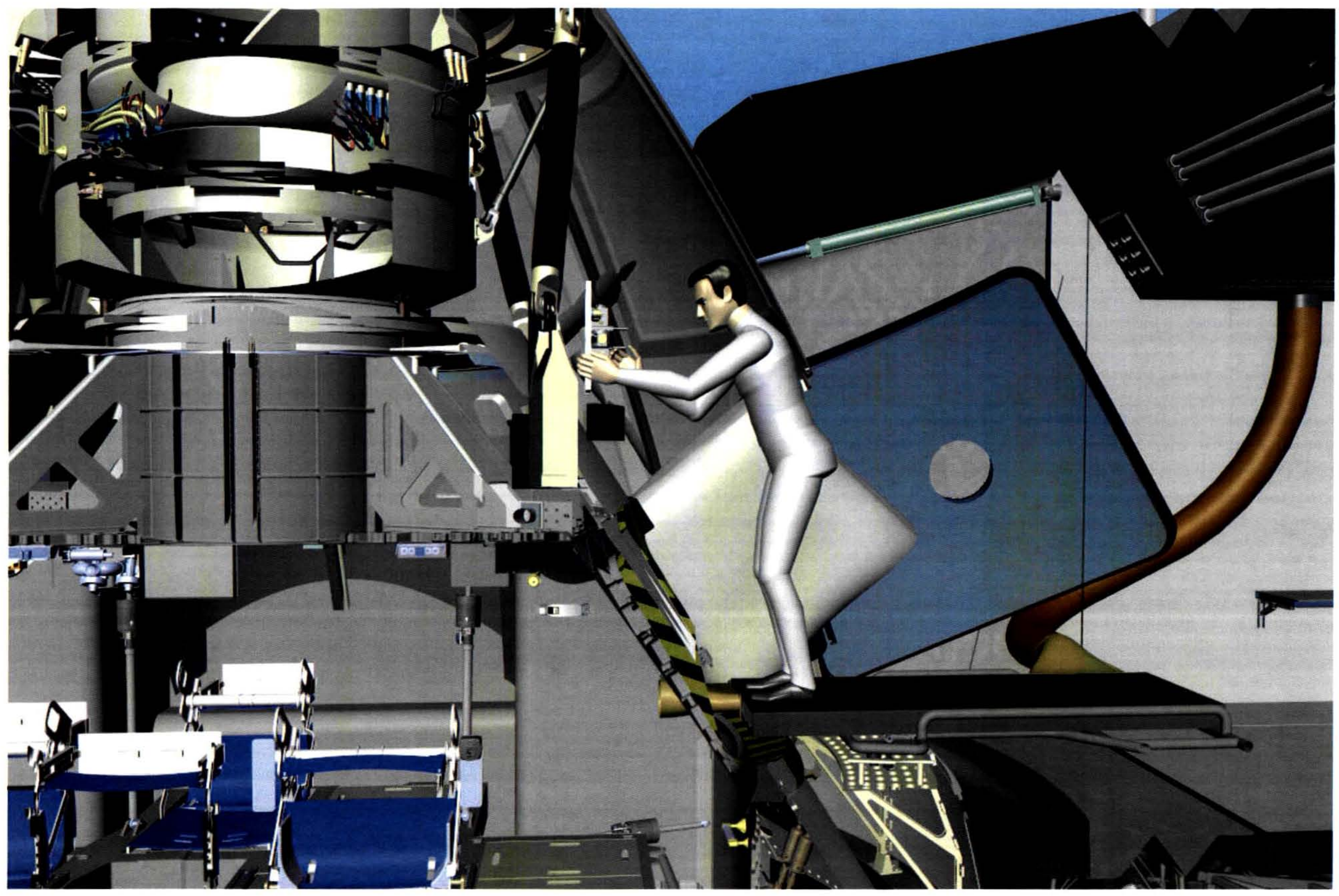

NOTE: Constellation ORION Project: High Bay Area with an excessive fall distance. There is no Personal Protection Equipment (PPE) or spotter present. For example, a NASA Safety Expert will evaluate this scenario as a 4 x 5 (Catastrophic Hazard-RED). 


\section{Conclusion}

- Research Questions Addressed

- Research Hypotheses Addressed

- Research Contributions Addressed

- Research Limitations

- It is confirmed that falls are preventable by multidimensional assessment and targeted intervention 


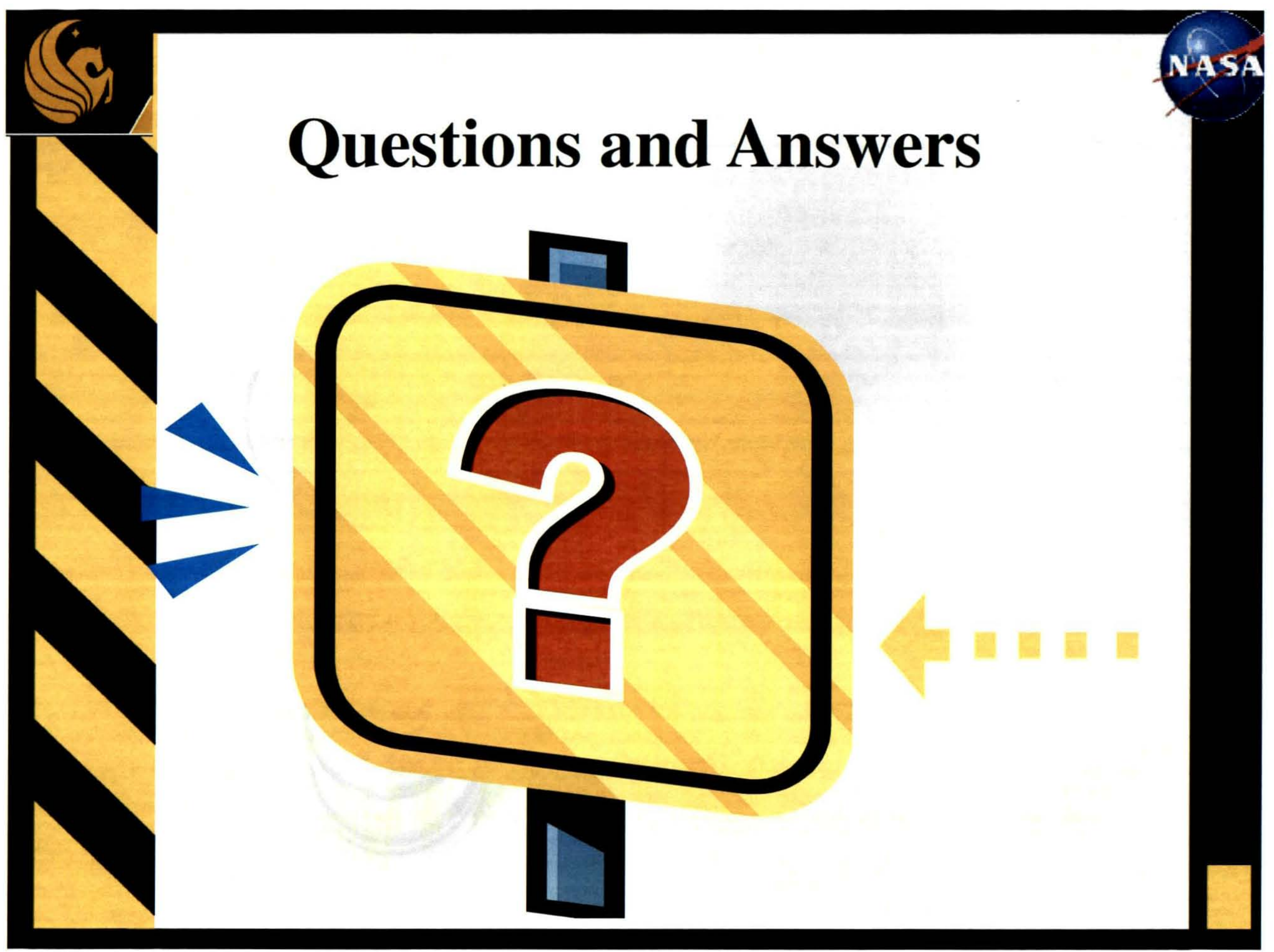

